\title{
Analysis of Flexural Toppling Failure of Anti-Dip Rock Slopes Due to Earthquakes
}

\author{
Hong Zhang ${ }^{1}$, Yihan $\mathrm{Wu}^{2}$, Shiting Huang ${ }^{2}$, Lu Zheng ${ }^{2,3}$ and Yuanbing Miao ${ }^{2 *}$ \\ ${ }^{1}$ College of Civil Engineering, Tongji University, Shanghai, China, ${ }^{2}$ College of Civil Engineering, Fuzhou University, Fuzhou, China, \\ ${ }^{3}$ Sichuan University-The Hong Kong Polytechnic University Institute for Disaster Management and Reconstruction, Sichuan \\ University, Chengdu, China
}

Flexural toppling is one of the failure modes of anti-dip rocks, is often triggered by seismic load, occurs haphazardly under an earthquake scenario, and is characterized by high speed and extreme energy, leading to catastrophic disaster consequences and huge losses. However, there is limited literature that reveals its failure mechanisms and describes the failure surface due to earthquakes. Therefore, based on the limit equilibrium analysis method, the horizontal pseudo-static load was applied to improve the geological mechanical model under gravity only, and the stability analysis process was derived.

OPEN ACCESS

Edited by:

Xiaodong $\mathrm{Fu}$,

State Key Laboratory of

Geomechanics and Geotechnical Engineering, Institute of Rock and Soil Mechanics (CAS), China

Reviewed by:

Zhenghu Zhang,

Dalian University of Technology, China

Tiexin Liu,

Dalian Maritime University, China

*Correspondence:

Yuanbing Miao

10241652@qq.com

Specialty section:

This article was submitted to

Geohazards and Georisks,

a section of the journal

Frontiers in Earth Science

Received: 07 December 2021 Accepted: 15 December 2021

Published: 31 January 2022

Citation:

Zhang $H$, Wu Y, Huang S, Zheng L and Miao Y (2022) Analysis of Flexural Toppling Failure of Anti-Dip Rock Slopes Due to Earthquakes. Front. Earth Sci. 9:831023. doi: 10.3389/feart.2021.831023
The failure surface and failure mode of the slope under different seismic loads were analyzed. The results indicated that, with the increasing seismic load, an increase in the number of rock layers with sliding failure increased the number of rock layers with cantilever toppling failure; in contrast, the number of rock layers with overlapping toppling failure decreased. The slope toe was more prone to sliding and the slope top was more prone to cantilever toppling under an earthquake, which decreased the stability of the anti-dip rock slope.

Keywords: anti-dip rock slope, flexural toppling, limit equilibrium, seismic load, stability analysis

\section{INTRODUCTION}

An anti-dip rock slope (Zuo et al., 2005) is a common geological feature worldwide, existing not only in mountainous areas, but also along engineered slopes such as highways, railways, water and hydropower stations, and mining projects. It usually experiences flexural toppling failure under the action of gravity. The corresponding toppling failure is a typical instability mode of rock slopes (Hungr et al., 2014). It has better stability than an inclined one, but is substantially more difficult to identify although the developed 3S technologies and AI algorithms (Huang, 2007; Huang et al., 2021a; Huang et al., 2021b). Its failure varies from several surface blocks toppling to large-scale toppling (Huang et al., 2017), and develops from slowly to extremely rapidly (Bobet, 1999). The failure of this type of rock slope is often triggered by seismic loads (Keefer, 1984; Keefer, 2002; Huang and Li, 2009; Xu et al., 2009). Various field investigations have indicated that the failure of anti-dip rock slopes occurs haphazardly under an earthquake scenario and is characterized by high speed and extreme energy, leading to catastrophic disaster consequences and huge losses (Xu et al., 2009; Zhao et al., 2010; Chen and Teng, 2011; Ka et al., 2011; Li et al., 2011; Huang et al., 2013a; Nonomura and Hasegawa, 2013), arousing widespread concern in society, especially since the 2008 Wenchuan earthquake. 


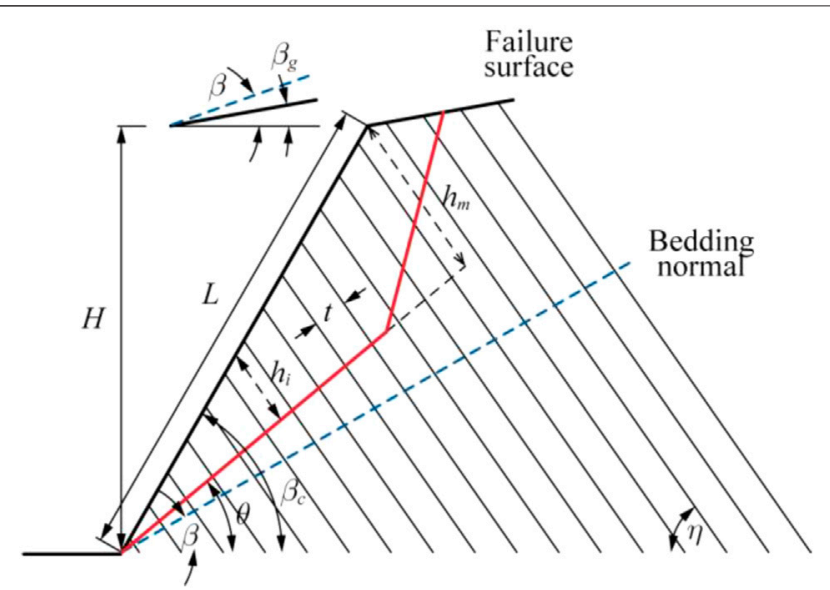

FIGURE 1 | Geological model of flexural toppling failure (modified from Chen et al. (2016).

Goodman and Bray (Goodman and Bray, 1976) summarized toppling failures of anti-dip rock slopes into three types: block toppling, flexural toppling, and blockflexural toppling. The methods used to investigate the stability of anti-dip rock slopes under seismic loads include field investigation as mentioned above, analytical solution, numerical simulation, and physical experiment.

Among them, in particular, shaking table tests, which have been proven to be an effective approach to study both the dynamic response and failure process of anti-dip rock slopes, have been extensive applied, especially with the last 10 years. Chen et al. (Chen et al., 2020) modeled block toppling by conducting a series of shaking table tests. Aydan and Amini (Aydan and Amini, 2009) investigated the effect of seismic loads on the failure of a single column and rock slopes with the potential of flexural toppling. Huang et al. (Huang et al., 2013b) modeled the failure process of the Guantan landslide induced by the Wenchuan earthquake using a shaking table test. Fan et al. (Fan et al., 2016) studied the dynamic response and failure mode of bedding and anti-dip model slopes with weak interlayers, the dip angle was gentle, $8^{\circ}$. Correspondingly, Li et al. (Li et al., 2017), as well as Liu et al. (Liu et al., 2021), carried out large-scale shaking table tests to study the dynamic response of steep bedding and anti-dip rock slopes, their dip angles were $60^{\circ}$, $65^{\circ}$, and $70^{\circ}$. Furthermore, Yang et al. (2012) and Feng et al. (2019) performed shaking table tests to investigate the dynamic response of the anti-dip slope model, considering not only the strata, but also the structural joints.

Meanwhile, numerical simulations were performed. YagodaBiran and Hatzor (Yagoda-Biran and Hatzor, 2013) proposed a failure mode diagram and verified it using discontinuous deformation analysis (DDA) to investigate the effect of pseudo-seismic loads on block toppling and sliding failure. Miki et al. (2010) simulated block toppling using the Niigata Chuetsu earthquake recorded by the coupled DDA-NNM method. Feng et al. (2019) performed DDA simulations to investigate block toppling under a sinusoidal wave. Zhang et al. (2015) conducted universal distinct element code (UDEC) simulations to study flexural toppling failures under strong motion records from Wenchuan, Ludian, and Minxian. Ning et al. (2019) and Liu et al. (2021) studied block-flexural toppling on anti-dip rock slopes under seismic load using UDEC and FLAC, respectively, by analyzing the failure mode process for a prototype slope of the corresponding large shaking table test.

From the view of theoretical solution, Liu and Chen (2010) adopted the concept of the transfer coefficient, and derived an analytical approach for assessing the block toppling failure of rock slopes due to earthquake, based on Goodman and Bray (Goodman and Bray, 1976). Guo et al. (2017) also proposed an analytical solution for the block toppling failure of rock slopes during an earthquake based on the limit equilibrium method. Zheng et al. (2014) presented explicit expressions for the condition that block slenderness is relatively large. Zhang et al. (2018) deduced the analytic formula of block-flexural topping failure, and investigated the effect on the failure mode and stability subjected to seismic loads.

With the implementation of the development strategy of China's vast western regions, there have been constructions of various large-scale infrastructures, and it is urgent to systematically study the problems of slope geological disasters under complex environments or extreme conditions. However, it is not difficult to point out that quantitative studies on toppling failure under dynamic loads are seldom reported in the current literature, compared to those on bedding landslides. Therefore, in this study, a mechanical model of anti-dip rock slopes was established with a horizontal pseudo-static load acting to analyze the slope failure mechanism and explode the failure surface under different seismic loads. The findings are of great scientific and engineering significance to prevent the deformation and instability of rock slopes, formulate earthquake prevention and disaster reduction plans and emergency response measures, and safeguard the construction and operation of major infrastructure.

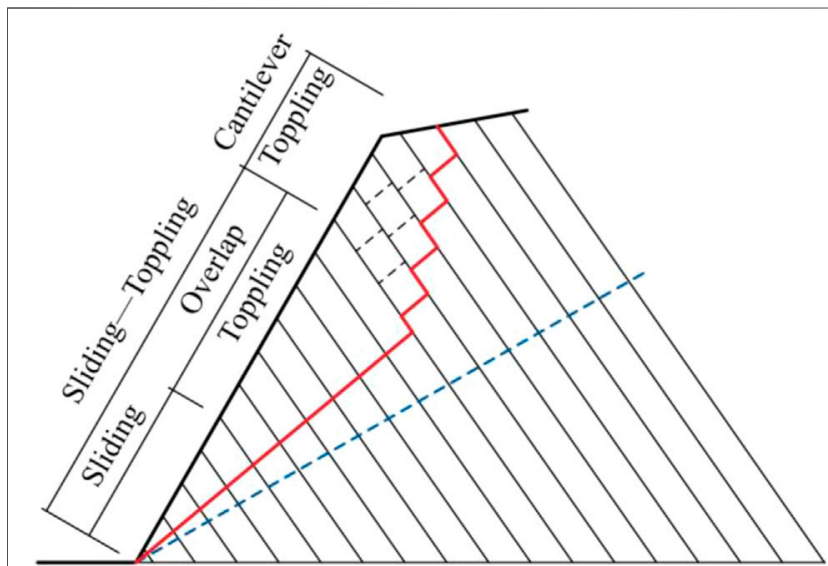

FIGURE 2 | Failure mode zoning of flexural toppling (modified from Chen et al. (2016). 


\section{ANALYSIS OF THE FLEXURAL TOPPLING FAILURE UNDER PSEUDO-SEISMIC LOAD}

\section{Geological Geometric Model}

Chen et al. (2016) developed a geological geometric model of flexural toppling failure of anti-dip rock slopes under gravity (Figures 1, 2). The limit equilibrium analysis method was used to carry out a theoretical analysis of the mechanical model of the flexural toppling failure of anti-dip rock slopes. This study introduced pseudo-seismic load to it to investigate the flexural toppling failure under an earthquake scenario. The failure surface was detected using the analytical method to explore the failure modes.

The intermediate parameters are defined as:

$$
\left\{\begin{array}{l}
\beta_{g r}=\beta-\beta_{g} \\
\beta_{c r}=\beta_{c}-\beta \\
\theta_{r}=\theta-\beta
\end{array}\right.
$$

Based on the geometric relationship, the slope length is:

$$
L=\frac{H}{\sin \beta_{c}}
$$

The rock height on the left of the failure reference plane is given as:

$$
h_{m}=L \cos \beta_{c r}\left(\tan \beta_{c r}-\tan \theta_{r}\right)
$$

The rock strata were numbered from the slope toe, and the rock stratum at the top of the slope is

$$
m=\operatorname{int}\left(\frac{L_{c} \cos \beta_{c r}-0.5 t}{t}\right)+1
$$

where int is the rounding function.

$$
L_{c}=\frac{\cos \theta_{r}}{\sin \left(\beta_{c r}-\cos \theta_{r}\right)_{r}} h_{m}
$$

Therefore, the height of any rock on the failure surface is:

$$
h_{i}= \begin{cases}h_{m}+(m-i)\left(\tan \theta_{r}+\tan \beta_{g r}\right) t & i \geq m \\ h_{m}-(m-i)\left(\tan \beta_{c r}-\tan \theta_{r}\right) t & i<m\end{cases}
$$

where $i$ is the rock number, $h_{m}$ is the height at the right of the top rock stratum, $t$ is the thickness of the rock stratum, $\beta$ is the angle of the surface normal, $\beta_{c}$ is the slope angle, $\beta_{g}$ is the natural slope angle, $\theta$ is the angle between the horizontal plane and the slidingtoppling zone, and $\eta$ is the angle of the rock strata.

The self-weight of any rock above the failure surface is given as:

$$
\begin{gathered}
w_{i}=\gamma h_{j} t \\
h_{j}=\frac{h_{i-1}+h_{i}}{2}
\end{gathered}
$$

where $\gamma$ is the unit weight of the rock mass.

\section{Analytical Method}

To simplify the mechanical analysis of flexural toppling failure in slope, the following assumptions were proposed based on the mechanism of flexural toppling failure:

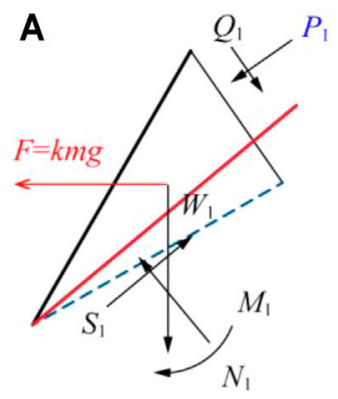

Sliding failure

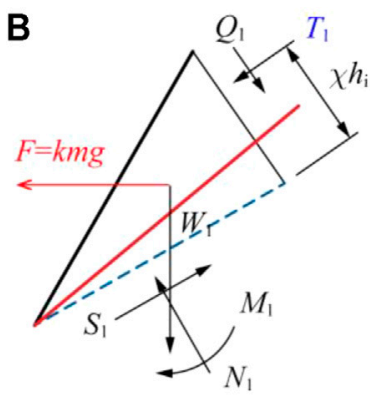

Toppling failure
FIGURE 3 | Limit equilibrium analysis of rock mass (A) Diagram of sliding failure in stratum layer; (B) Diagram of toppling failure, \#1 at slope toe under horizontal pseudo-static load.

1) Failure mode zoning: The rock slop failure started from the slope toe and the failure zones were divided into sliding, overlap toppling, and cantilever toppling zones.

2) Reference failure surface: The failure surface of flexural toppling failure of anti-dip rock slopes was a fold line. The boundary between the overlap and cantilever toppling zones determined the point of contra flexure; the failure was step-type above the boundary and straight line-type below the boundary.

3) When the rocks in the sliding-toppling zone failed, the interface and bottom of the adjacent rock layer met the limit friction equilibrium conditions.

4) Taking the rock strata layer as the basic element, the force on the layer was simplified as a concentrated force on point $\chi h_{i}, \chi \in(0,1)$

5) The safety factor of rock layers with failure potential was equal to the safety factor of the slope.

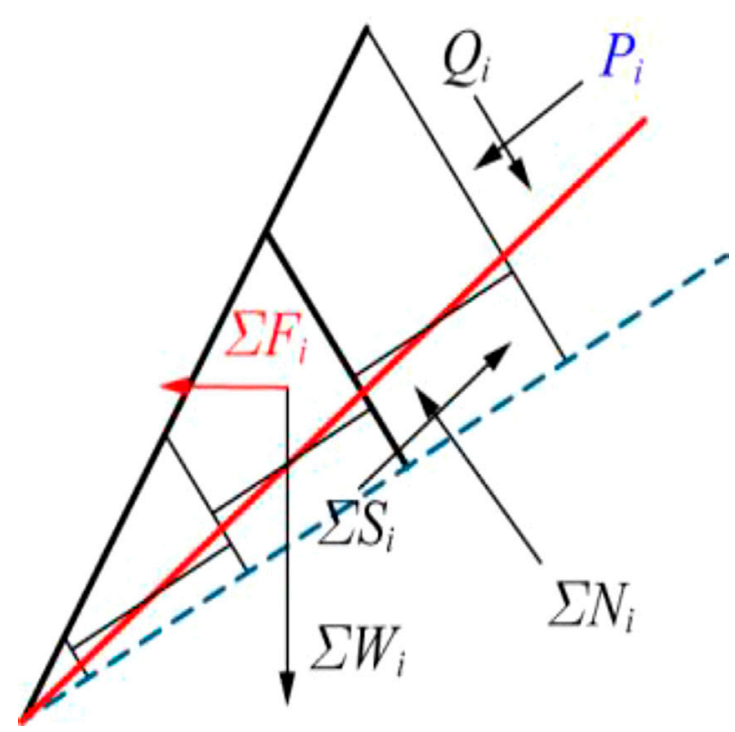

FIGURE 4 | Limit equilibrium analysis of rock mass shear failure below stratum layer \#i under horizontal pseudo-static load. 


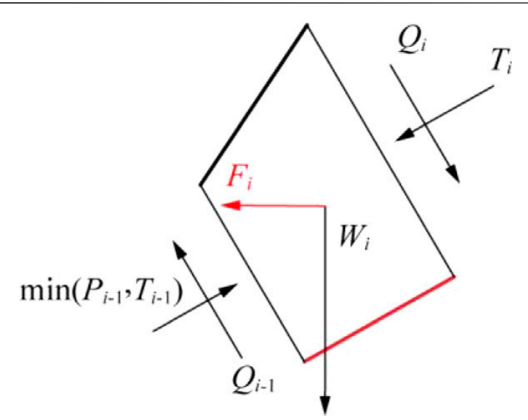

FIGURE 5 | Limit equilibrium analysis of rock mass toppling failure in stratum layer \#i under horizontal pseudo-static load.

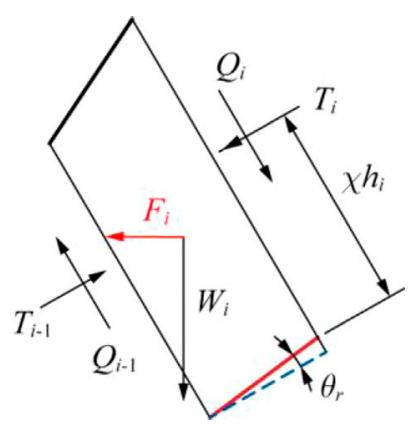

FIGURE 6 | Limit equilibrium analysis of rock mass toppling failure above stratum layer \#i under horizontal pseudo-static load.

Since the slope failure started at the slope toe, a stability analysis procedure was performed from the slope toe to the top.

First, the limit equilibrium analysis of rock strata layer \# 1 at the slope toe was carried out under the horizontal pseudo-static load $(F=k m g)$. The models are shown in Figure 3, where $Q_{1}$ is the tangential force between strata, $Q_{1}=P_{1} \tan \varphi_{j}$ (sliding failure) or $Q_{1}=T_{1} \tan \varphi_{j}$ (toppling failure) $\left(\varphi_{j}\right.$ is the internal friction angle of between strata), $W_{1}$ is self-gravity, and $S_{1}$ and $N_{1}$ are the tangential and normal forces at the bottom of the layer, respectively.

When the rock strata layer at the slope toe was analyzed according to the shear-sliding failure mode, the limit equilibrium analysis method was used to analyze the force along the failure surface. When rock strata layer \# 1 experienced sliding failure, the minimum force of rock strata layer \#2 pushing on rock strata layer \#1 is given as:

$$
\begin{gathered}
P_{1}=\frac{w_{1} \cos \theta\left(\tan \varphi-F_{S} \tan \theta\right)+\frac{c t}{\cos \theta_{r}}-F_{1} \cos \theta\left(F_{s}+\tan \theta \tan \varphi_{j}\right)}{F_{s} \cos \theta_{r}\left(1+\tan \varphi_{j} \tan \theta_{r}\right)+\tan \varphi \cos \theta_{r}\left(\tan \theta_{r}-\tan \varphi_{j}\right)} \\
F_{S}=\frac{N_{1} \tan \varphi+\frac{c t}{\cos \theta_{r}}}{w_{1} \sin \theta+P_{1} \cos \theta_{r}+P_{1} \tan \varphi_{j} \sin \theta_{r}+F_{1} \cos \theta}
\end{gathered}
$$

where $F_{S}$ is the safety factor of the slope, $F_{S}=$ total anti-sliding force/total sliding force, $c$ is the cohesion between the rock masses, and $\varphi$ is the internal friction angle of the rock.
The rock layer at the slope toe was analyzed according to flexural toppling, and the rotating axis was at the center of the bottom surface. According to the beam-plate bending theory, the minimum force of rock strata layer \#2 acts on rock strata layer \#1 when rock layer \#1 is toppled:

$$
T_{1}=\frac{\left(\frac{\sigma_{t}}{F_{S}}+\frac{w_{1} \cos \beta-F \sin \beta}{t}\right) \cdot \frac{2 I}{t}-w_{1} \sin \beta \cdot \frac{h_{1}}{2}-F \cos \beta \cdot \frac{h_{1}}{2}}{\chi h_{1}-\frac{t}{2} \tan \varphi_{j}}
$$

where $\sigma_{t}$ is the tensile strength of the rock; and $I$ is the polar inertia moment of the rock per unit width, $I=\frac{1}{12} t^{3}$.

Then, the failure mode of rock strata layer \# 1 at the slope toe is:

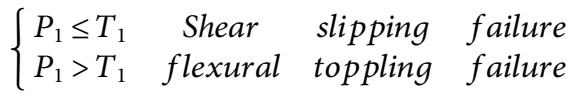

Similarly, under the horizontal pseudo-static force, shear sliding failure occurred below rock strata layer $i$. As shown in Figure 4, the minimum force required from the upper rock strata layers is given as:

$P_{1}=\frac{\sum_{j=1}^{i} w_{j} \cos \theta\left(\tan \varphi-F_{S} \tan \theta\right)+\frac{i c t}{\cos \theta_{r}}-\sum_{j=1}^{i} F_{j} \cos \theta\left(F_{s}+\tan \theta \tan \varphi\right)}{F_{S} \cos \theta_{r}\left(1+\tan \varphi_{j} \tan \theta_{r}\right)+\tan \varphi \cos \theta_{r}\left(\tan \theta_{r}-\tan \varphi_{j}\right)}$

Flexural toppling failure occurred below rock strata layer $i$ (Figure 5). The minimum force required from upper rock layers is:

$$
\begin{gathered}
T_{i}=\frac{1}{\chi h_{1}-\frac{t}{2} \tan \varphi_{j}}\left[\min \left(P_{i-1}, T_{i-1}\right)\left(\chi h_{i-1}+\frac{t}{2} \tan \varphi_{j}\right)+\left(\frac{\sigma_{t}}{F_{S}}\right.\right. \\
\left.\left.+\frac{w_{1} \cos \beta-F_{i} \sin \beta}{t}\right) \cdot \frac{2 I}{t}-w_{1} \sin \beta \cdot \frac{h_{j}}{2}-F_{i} \cos \beta \cdot \frac{h_{j}}{2}\right]
\end{gathered}
$$

It can be seen from the above two equations that when the rock strata layers $n_{s t}$ and $n_{s t+1}$ failed, the rock layer $n_{s t}$ was the boundary of the overlap toppling zone and the sliding zone, the force of the upper rock strata layers should satisfy as:

$$
\left\{\begin{array}{l}
P_{n_{s t}} \leq T_{n_{s t}} \\
P_{n_{s t}+1}>T_{n_{s t}+1}
\end{array}\right.
$$

The mechanical model of the overlap toppling zone is shown in Figure 6. For the rock layer to experience flexural toppling failure, the minimum force required from the upper rock layers is:

$$
\begin{array}{r}
T_{i}=\frac{1}{\chi h_{1}-\frac{t}{2} \tan \varphi_{j}}\left[T_{i-1}\left(\chi h_{i-1}+\frac{t}{2} \tan \varphi_{j}\right)\right. \\
+\left(\sigma_{t}+\frac{w_{1} \cos \beta-F_{i} \sin \beta}{t}\right) \cdot \frac{2 I}{t} \\
\left.-w_{1} \sin \beta \cdot \frac{h_{j}}{2}-F_{i} \cos \beta \cdot \frac{h_{j}}{2}\right]
\end{array}
$$

The boundary of the overlap toppling zone and cantilever toppling zone (rock layer $n_{c t}$ ) is determined by the following system of inequalities: 


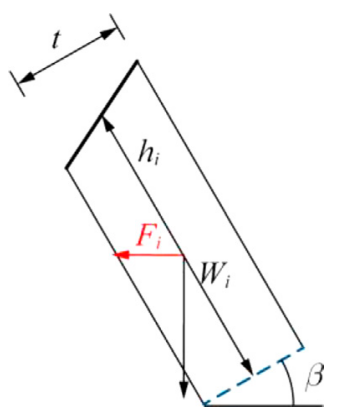

FIGURE 7 | Critical instability length.

$$
\left\{\begin{array}{l}
T_{n_{c t}} \geq 0 \\
T_{n_{s t}+1}<0
\end{array}\right.
$$

If these inequalities are satisfied, the boundary range can be determined.

After the rock layer in the sliding zone and the cantilever toppling zone were damaged, a cantilever section appeared in the trailing edge. There was no contact between the rock layer in the cantilever toppling zone; hence, the interlayer force became zero (Figure 7). The stability analysis was converted into an "independent cantilever beam" problem. Lu et al. (Lu et al., 2012) derived the equation of critical fracture depth of a single rock layer based on the "independent cantilever beam model." On this basis, a horizontal quasi-static force was applied in this study, as shown in Figure 7, and the critical instability length was obtained as follows:

$$
h_{c r}=\frac{t \cos \beta-k(3 \cos \beta+t \sin \beta)+\sqrt{t^{2} \cos ^{2} \beta+12 t \sin \beta \sigma_{t} / \gamma+\xi(k)}}{6 \sin \beta}
$$

where,

$$
\begin{aligned}
\xi(k)= & k^{2}\left(9 \cos ^{2} \beta+t^{2} \sin ^{2} \beta+6 t \sin \beta \cos \beta\right)+k\left(6 t \cos ^{2} \beta\right. \\
& \left.+2 t^{2} \sin \beta \cos \beta\right)
\end{aligned}
$$

When the height of the rock layer in the cantilever toppling zone was greater than $h_{s r}$, a multi-level fracture may occur. When the fracture depth of all rock layers was determined, the midpoints of the last fracture surface of each rock layer were connected to obtain the complete failure surface.

\section{Determination of Slope Stability}

An iterative calculation was carried out using Eqs. 13, 14 considering the slope toe to the slope top. The boundary of the sliding zone and the overlap toppling zone was determined using Eq. 15. Then, the force on the flexural toppling zone was obtained using Eq. 16. If Eq. 17 is satisfied, the rock layer $n_{c t}$ is found. If Eq. 17 is not satisfied, there is no cantilever section, that is, a force is needed for the failure of each rock layer. The last rock layer needs additional external force $F_{0}$ to meet the force requirements. Since this external force does not exist for the

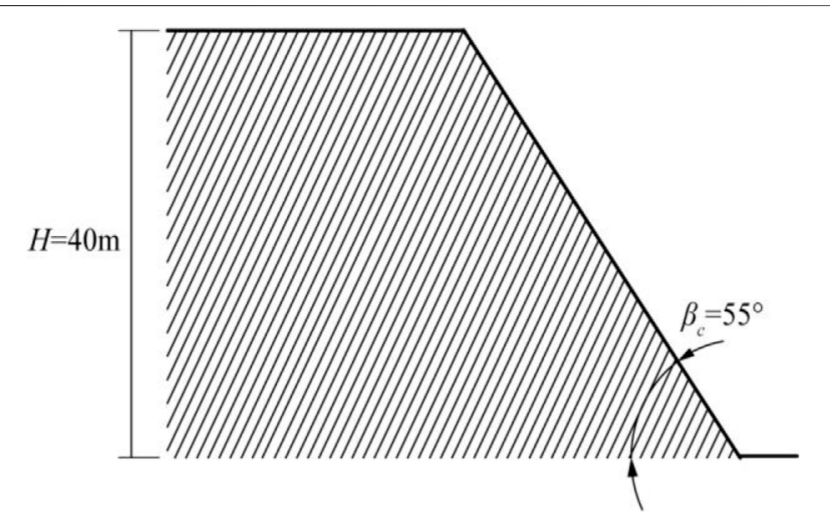

FIGURE 8 | Geometric description of the anti-dip rock slope model in southern Anhui.

actual slope, it can be used to determine the slope stability as represented in the equation below.

$$
\begin{cases}F_{0}>0 & \text { (Unstable) } \\ F_{0}=0 & \text { (Limit equilibrium state) } \\ F_{0}<0 & \text { (Stablize) }\end{cases}
$$

where $F_{0}$ is the minimum external force required for slope failure, and

$$
\left\{\begin{array}{l}
F_{i}=\min \left(T_{i}, P_{i}\right) \\
F_{0}=\min \left(F_{i}\right)
\end{array}\right.
$$

In summary, when $F_{0}>0$, the slope is unstable; $F_{0}=0$, the slope is of the limit equilibrium state, and $F_{0}<0$, the slope is about to deform and fail. Where rock strata layers $\left[1, n_{s t}\right]$ have a sliding failure, rock strata layers $\left[n_{s t}, n_{c t}\right]$ have overlap toppling failure, and layer $n_{c t}$ and above have cantilever toppling failure.

\section{Failure Surface Search}

Based on the above mechanical analysis, the key parameter to determining the failure surface is to find the angle $\theta_{r}$ between the failure surface and the rock surface normal, as well as the two boundary rock layers: 1) boundary of the sliding zone and the overlap toppling zone $\left.n_{s t}, 2\right)$ boundary of the overlap toppling zone and the cantilever toppling zone $n_{c t}$. Therefore, the safety factor of the slope was determined first. Based on the geometric slope model and mechanical analysis, the safety factor of the slope is a function of the geometric parameters, mechanical parameters, strength parameters, failure surface, and other loads of the slope:

$$
F_{S}=F_{S}\left(H, \beta_{c}, \beta_{g}, \gamma, c, \varphi, \varphi_{j}, \sigma_{t}, t, \theta_{r}, F\right)
$$

where $F$ is other loads on the slope.

For a given slope, except for $\theta_{r}$, all parameters are known; hence, to calculate the slope and other parameters, the value of $\theta_{r}$ is first determined. 
TABLE 1 | Calculation table of failure plane search of the south Anhui slope under the action of a horizontal quasi-static force.

\begin{tabular}{ccccc}
\hline No. & $\boldsymbol{r}$ & $\begin{array}{c}\text { Safety } \\
\text { coefficient } \boldsymbol{F}_{\boldsymbol{s}}\end{array}$ & $\begin{array}{c}\text { First } \\
\text { boundary } \boldsymbol{n}_{\boldsymbol{s t}}\end{array}$ & $\begin{array}{c}\text { Second } \\
\text { boundary } \boldsymbol{n}_{\boldsymbol{c t}}\end{array}$ \\
\hline 1 & 0.0 & 0.974 & 5 & 25 \\
2 & 1.0 & 0.976 & 6 & 26 \\
3 & 1.3 & 0.998 & 6 & 26 \\
4 & 1.4 & 1.006 & 6 & 26 \\
5 & 1.5 & 1.015 & 6 & 26 \\
6 & 1.6 & 0.950 & 6 & 27 \\
7 & 1.7 & 1.032 & 6 & 26 \\
8 & 2.0 & 0.982 & 6 & 27 \\
9 & 4.0 & 1.011 & 8 & 29
\end{tabular}

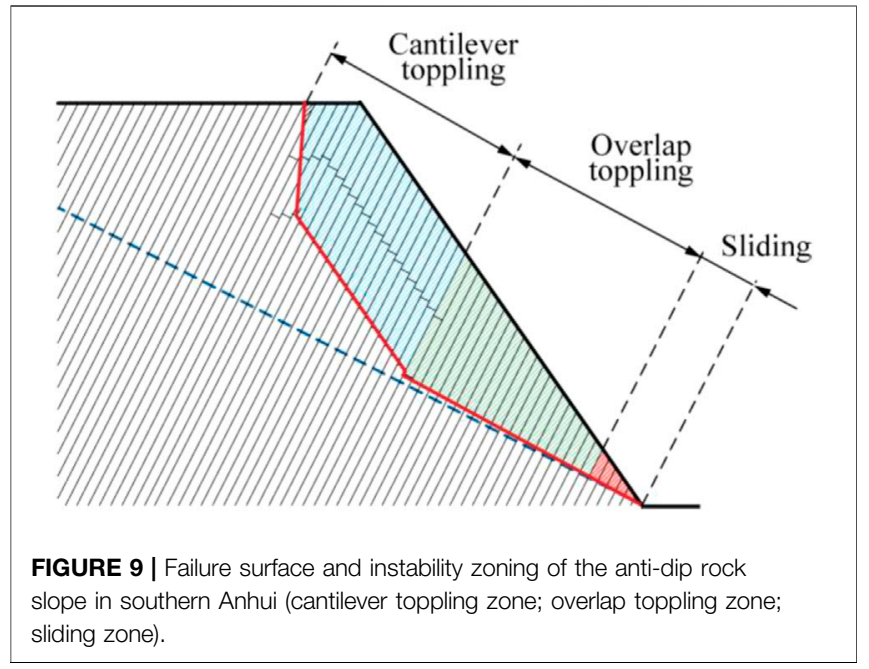

The cut slope surface was set as the upper searching limit, while the surface normal was the lower limit; therefore, the failure surface could be obtained based on the condition of minimum $F_{S}$.

Step 1: For a given initial $\theta_{r 0}$, the value of $F_{S}$ is changed using the bisection method. The values of $F_{S}, n_{s t}$, and $n_{c t}$ that cause slope instability at $\theta_{r 0}$ when $F_{0}=0$ are obtained, and the initial failure surface is also obtained. A safety factor can also be obtained; however, it is not necessarily the minimum value. Hence, the next search is carried out as follows:

Step i: Similarly, for a given value $\theta_{r s}\left(\theta_{r s}=\theta_{r 0}+i \Delta \theta_{r}\right), \Delta \theta_{r}$ is the calculation step length, and Fs is changed using the bisection method. Then, the values of $F_{S i}, n_{s t}$, and $n_{c t}$ corresponding to $\theta_{r s}$ at step $I$ are obtained, and the failure surface of step $i$ is determined.

Final step: When the angle is $\theta_{r}$, the corresponding $F_{S}$ reaches the smallest value. Then $\theta_{r}$ is the angle of the failure surface, and the $F_{S}, n_{s t}$, and $n_{c t}$ are the final boundary layers.

\section{CASE ANALYSIS}

To verify the reliability of the method proposed in this study, the anti-dip rock slope in southern Anhui was taken as a case study. The slope model is shown in Figure 8.

The slope model showed the following parameters: height $H=$ $40.0 \mathrm{~m}$, distance between structural planes $t=1.0 \mathrm{~m}$, rock unit weight $\gamma$ $=27.0 \mathrm{kN} / \mathrm{m}^{3}$; natural slope $\beta_{g}=0^{\circ}$, slope inclination $\beta_{c}=55^{\circ}$, bedding layer normal inclination $\beta=27^{\circ}$, the internal friction angle of the rock mass $\varphi_{\text {rock }}=45^{\circ}$ the layer internal friction angle $\varphi_{\text {layer }}=18^{\circ}$; the rock cohesion $c=0.10 \mathrm{MPa}$, the tensile strength of the rock $\sigma_{t}=1.5 \mathrm{MPa}$, the elastic modulus $E=9.98 \mathrm{GPa}$; and the Poisson's ratio $v=0.30$.

A horizontal quasi-static force $F=0.2 \mathrm{~g}$ was applied to the slope, and the above search method was used to determine the failure surface (Table 1). The critical instability length was $6.46 \mathrm{~m}$, implying that a secondary fracture occurred in the cantilever toppling zone, and the failure area increased significantly. The failure surface is shown in Figure 9.

To further explore the influences of seismic load on the failure of anti-dip rock slopes, the slope failure modes under different seismic loads, i.e., $0.4,0.6,0.8$, and $1.0 \mathrm{~g}$ were analyzed, and the results are shown in Table 2. According to the results, the slope failure surface and failure zone are identified in Figure 10. The red, green, and blue areas are the sliding, overlap toppling, and cantilever toppling zones, respectively.

With the increasing seismic load, the failure surface of the slidingtoppling zone decreased significantly, and as the critical fracture depth of the cantilever toppling zone decreased, the failure surface of the cantilever toppling zone increased significantly. Moreover, as the sliding zone increased, the overlap toppling zone decreased, and the cantilever toppling zone consequently increased. The multi-level fracture occurred when the seismic acceleration was large. Therefore, the stability of rock slopes decreased under seismic loads. As the number of rock strata layers with overlap toppling failure decreased, the number of rock layers with cantilever toppling and rock layers with sliding failure increased. The axial stress of the rock block was increased and became closer to reaching the tensile strength of the rock block due to the influence of seismic force. Hence, combined with the enhanced sliding potential of the sloping block, the cantilever toppling rock increased significantly.

TABLE 2 | Stability and zoning of the anti-dip rock slope in southern Anhui under different seismic loads.

\begin{tabular}{|c|c|c|c|c|c|c|}
\hline Acceleration $(g)$ & Fs & $r\left({ }^{\circ}\right)$ & Sliding & Overlap toppling & Cantilever toppling & $h_{c r}(\mathrm{~m})$ \\
\hline 0.2 & 0.950 & 1.60 & 6 & 21 & 21 & 6.46 \\
\hline 0.4 & 0.891 & 1.00 & 7 & 16 & 29 & 6.26 \\
\hline 0.6 & 0.887 & 0.00 & 7 & 12 & 33 & 6.04 \\
\hline 0.8 & 0.854 & 0.00 & 8 & 9 & 35 & 5.82 \\
\hline 1 & 0.845 & 0.00 & 9 & 6 & 38 & 5.62 \\
\hline
\end{tabular}



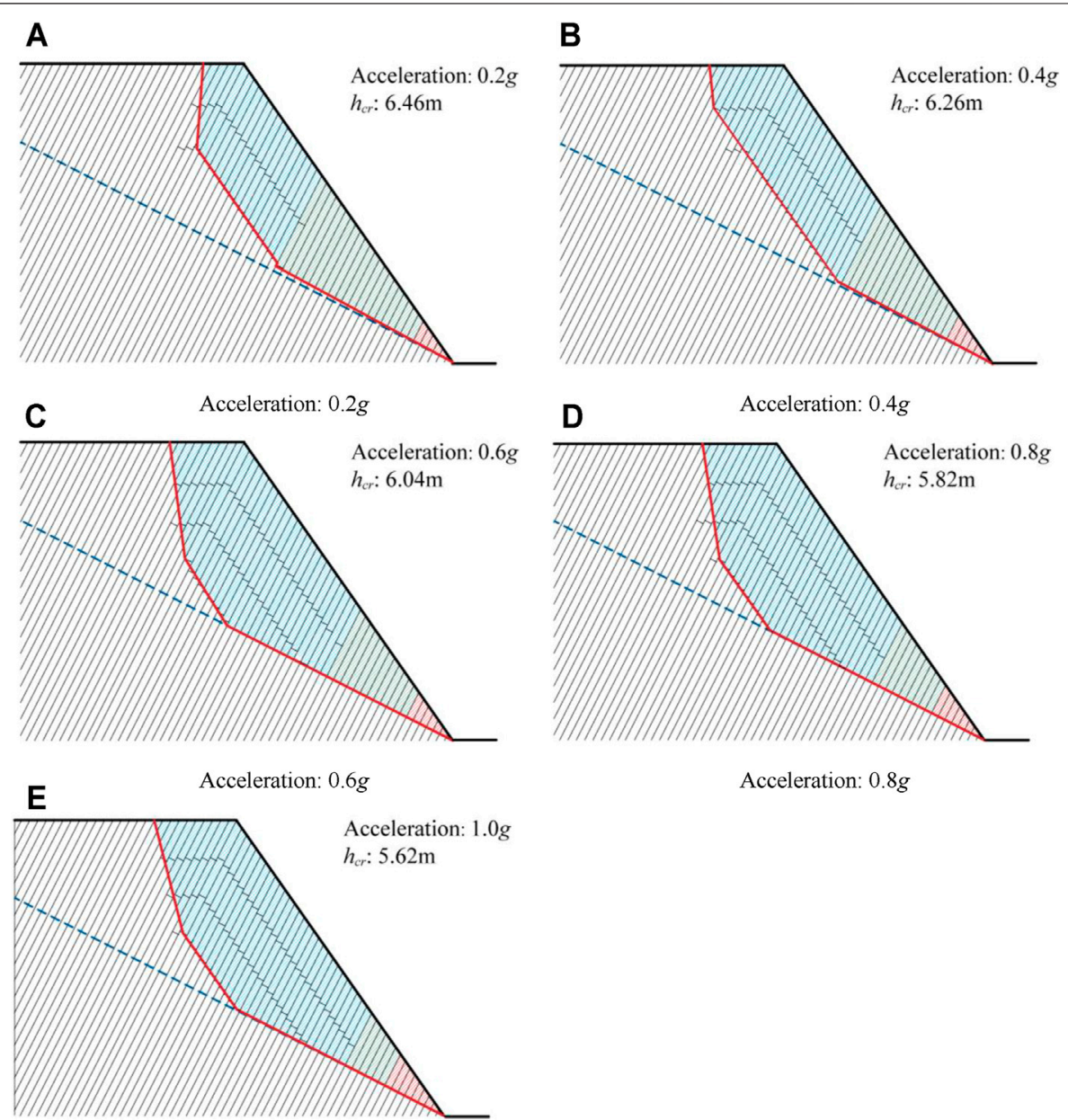

Acceleration: $0.8 g$

Acceleration: $1.0 \mathrm{~g}$

FIGURE 10 | Stability analysis of the anti-dip rock slope in southern Anhui under different seismic loads. (A) Stability analysis at $0.2 \mathrm{~g}$ acceleration; (B) Stability analysis at $0.4 \mathrm{~g}$ acceleration; (C) Stability analysis at $0.6 \mathrm{~g}$ acceleration; (D) Stability analysis at $0.8 \mathrm{~g}$ acceleration; (E) Stability analysis at $1.0 \mathrm{~g}$ acceleration.

\section{CONCLUSION}

In this paper, the pseudo-static method was used to establish the mechanical model of an anti-dip rock slope, analyze the failure mode and mechanism, explore the failure surface and evaluate the stability of the slope under different seismic loads, and obtain the following main conclusions:

1) The slope stability decreased under seismic load, and with the increasing seismic load, the sliding area increased, whereas the overlap toppling zone decreased.

2) The decrease in the critical fracture depth of the cantilever toppling zone firstly increased the area of the cantilever toppling zone, but the area finally decreased under a significant strong earthquake scenario.

3) An increase in the number of rock layers with sliding failure increased the number of rock layers with cantilever toppling failure; in contrast, the number of rock layers with overlapping toppling failure decreased.

\section{DATA AVAILABILITY STATEMENT}

The raw data supporting the conclusions of this article will be made available by the authors, without undue reservation.

\section{AUTHOR CONTRIBUTIONS}

HZ: Methodology, software, validation, investigation, data curation, visualization, writing-review and editing; YW: Software, validation, investigation, visualization, writing-review and editing; $\mathrm{SH}$ : Investigation, visualization, writing; LZ: Conceptualization, investigation, visualization, writing, project 
administration, funding acquisition; YM: Methodology, writingreview and editing, supervision.

\section{FUNDING}

This study was funded by the National Key R\&D Program of China (No. 2017YFC1501001-03), the National Natural Science

\section{REFERENCES}

Aydan, O., and Amini, M. (2009). An Experimental Study on Rock Slopes against Fexural Toppling Failure under Dynamic Loading and Some Theoretical Considerations for its Stability Assessment[J]. J. Sch. Mar. Sci. Technol. 7 (2), 25-40.

Bobet, A. (1999). Analytical Solutions for Toppling Failure. Int. J. Rock Mech. Mining Sci. 36 (7), 971-980. doi:10.1016/s0148-9062(99)00059-5

Chen, C.-C., Li, H.-H., Chiu, Y.-C., and Tsai, Y.-K. (2020). Dynamic Response of a Physical Anti-dip Rock Slope Model Revealed by Shaking Table Tests. Eng. Geology. 277, 105772. doi:10.1016/j.enggeo.2020.105772

Chen, C. X., Zheng, Y., and Sun, C. Y. (2016). An Analytical Approach on Flexural Toppling Failure of Counter-tilt Slopes of Layered Rock[J]. Chin. J. Rock Mech. Eng. 35 (11), 2174-2187. doi:10.13722/j.cnki.jrme.2016.1001

Chen, Y. M., and Teng, G. L. (2011). A Preliminary Discussion on the Characteristics of Landslide-Collapse Disaster Induced by Wenchuan Earthquake in Gansu and Countermeasures for Disaster Mitigation [J]. Northwest. Seismological J. 33 (B08), 451-455. doi:10.3969/j.issn.10000844.2011.z1.097

Fan, G., Zhang, J., Wu, J., and Yan, K. (2016). Dynamic Response and Dynamic Failure Mode of a Weak Intercalated Rock Slope Using a Shaking Table. Rock Mech. Rock Eng. 49, 3243-3256. doi:10.1007/s00603-016-0971-7

Feng, X., Jiang, Q., Zhang, X., and Zhang, H. (2019). Shaking Table Model Test on the Dynamic Response of Anti-dip Rock Slope. Geotech Geol. Eng. 37, 1211-1221. doi:10.1007/s10706-018-0679-4

Goodman, R. E., and Bray, J. W. (1976). "Toppling of Rock Slopes[C]," in Proceedings of the Specialty Conference on Rock Engineering for Foundations and Slopes (Boulder: American Society of Civil Engineering), 2, 739-760.

Guo, S., Qi, S., Yang, G., Zhang, S., and Saroglou, C. (2017). An Analytical Solution for Block Toppling Failure of Rock Slopes during an Earthquake. Appl. Sci. 7 (10), 1008. doi:10.3390/app7101008

Huang, F., Huang, J., Jiang, S., and Zhou, C. (2017). Landslide Displacement Prediction Based on Multivariate Chaotic Model and Extreme Learning Machine. Eng. Geology. 218, 173-186. doi:10.1016/j.enggeo.2017.01.016

Huang, F., Tao, S., Chang, Z., Huang, J., Fan, X., Jiang, S.-H., et al. (2021). Efficient and Automatic Extraction of Slope Units Based on Multi-Scale Segmentation Method for Landslide Assessments. Landslides 18, 3715-3731. doi:10.1007/ s10346-021-01756-9

Huang, F., Yan, J., Fan, X., Yao, C., Huang, J., Chen, W., et al. (2021). Uncertainty Pattern in Landslide Susceptibility Prediction Modelling: Effects of Different Landslide Boundaries and Spatial Shape Expressions. Geosci. Front. 2021, 101317. doi:10.1016/j.gsf.2021.101317

Huang, R. Q. (2007). Large-scale Landslides and Their Sliding Mechanisms in China since the $20^{\text {th }}$ Century[J]. Chin. J. Rock Mech. Eng. 26 (3), 433-454. doi:10.3321/j.issn:1000-6915.2007.03.001

Huang, R. Q., and Li, W. L. (2009). Analysis on the Number and Density of Landslides Triggered by the 2008 Wenchuan Earthquake, China[J]. J. Geol. Hazards Environ. Preservation 20 (3), 1-7.

Huang, R., Zhao, J., Ju, N., Li, G., Lee, M. L., and Li, Y. (2013). Analysis of an Antidip Landslide Triggered by the 2008 Wenchuan Earthquake in China. Nat. Hazards 68 (2), 1021-1039. doi:10.1007/s11069-013-0671-5

Huang, R., Zhao, J., Ju, N., Li, G., Lee, M. L., and Li, Y. (2013). Analysis of an Antidip Landslide Triggered by the 2008 Wenchuan Earthquake in China. Nat. Hazards 68, 1021-1039. doi:10.1007/s11069-013-0671-5
Foundation of China (No. 41977233), and the Scientific Research Foundation of Fuzhou University (No. XRC-18053).

\section{ACKNOWLEDGMENTS}

Thanks are due to Mr. Zhiyuan Zhu for assistance with editing the manuscript and preparing the figures to this paper.

Hungr, O., Leroueil, S., and Picarelli, L. (2014). The Varnes Classification of Landslide Types, an Update. Landslides 11 (2), 167-194. doi:10.1007/s10346013-0436-y

Ka, M. C., Chen, R. S., Wu, W. J., and Liu, G. (2011). Analysis on Features of Earthquake-Induced Landslide in Heavy Layer and Anti-dip Stratified Rock Slope[J]. Northwest. Seismological J. 33 (S), 408-412. doi:10.3969/j.issn.10000844.2011.z1.088

Keefer, D. K. (2002). Investigating Landslides Caused by Earthquakes - A Historical Review[J]. Surv. Geophys. 23 (6), 473-510. doi:10.1023/a:1021274710840

Keefer, D. K. (1984). Landslides Caused by Earthquakes. Geol. Soc. America Bull. 95, 406-421. doi:10.1130/0016-7606(1984)95<406:lcbe>2.0.co;2

Li, G., Huang, R. Q., Ju, N. P., Zhao, J. J., and Jia, J. (2011). Cause Mechanism of Giant Anti-incline Ganhekou Landslide Induced by Wenchuan Earthquake [J]. Water Resour. Power 29 (4), 118-121. doi:10.3969/j.issn.10007709.2011.04.039

Li, L.-q., Ju, N.-p., Zhang, S., and Deng, X.-x. (2017). Shaking Table Test to Assess Seismic Response Differences between Steep Bedding and Toppling Rock Slopes. Bull. Eng. Geol. Environ. 78, 519-531. doi:10.1007/s10064-0171186-1

Liu, C. H., and Chen, C. X. (2010). Analysis of Toppling Failure of Rock Slopes Due to Earthquake[J]. Chin. J. Rock Mech. Eng. 29 (z1), 3193-3198. CNKI:SUN: YSLX.0.2010-S1-088.

Liu, H., Zhao, Y., Dong, J., and Wang, Z. (2021). Experimental Study of the Dynamic Response and Failure Mode of Anti-dip Rock Slopes. Bull. Eng. Geol. Environ. 80, 6583-6596. doi:10.1007/s10064-021-02313-3

Lu, H. F., Liu, Q. S., and Chen, C. X. (2012). Improvement of Cantilever Beam Limit Equilibrium Model of Counter-tilt Rock Slopes[J]. Rock Soil Mech. 33 (2), 577-584. doi:10.3969/j.issn.1000-7598.2012.02.040

Miki, S., Sasaki, T., Koyama, T., Nishiyama, S., and Ohnishi, Y. (2010). Development of Coupled Discontinuous Deformation Analysis and Numerical Manifold Method (NMM-DDA)[J]. Int. J. Comput. Methods 7 (1), 131-150. doi:10.1142/s021987621000209x

Ning, Y., Zhang, G., Tang, H., Shen, W., and Shen, P. (2019). Process Analysis of Toppling Failure on Anti-dip Rock Slopes under Seismic Load in Southwest China. Rock Mech. Rock Eng. 52, 4439-4455. doi:10.1007/s00603-01901855-Z

Nonomura, A., and Hasegawa, S. (2013). Regional Extraction of Flexural-Toppled Slopes in Epicentral Regions of Subduction Earthquakes along the Nankai Trough Using DEMs. Environ. Earth Sci. 68, 139-149. doi:10.1007/s12665-012$1722-\mathrm{z}$

Xu, Q., Pei, X. J., and Huang, R. Q. (2009). Large-scale Landslides Induced by Wenchuan earthquake[M]. Beijing: Science Press. doi:10.3799/dqkx.2011.119

Yagoda-Biran, G., and Hatzor, Y. H. (2013). A New Failure Mode Chart for Toppling and Sliding with Consideration of Earthquake Inertia Force. Int. J. Rock Mech. Mining Sci. 64, 122-131. doi:10.1016/j.ijrmms.2013.08.035

Yang, G. X., Ye, H. L., Wu, F. Q., Qi, S. W., and Dong, J. Y. (2012). Shaking Table Model Test on Dynamic Response Characteristics and Failure Mechanism of Anti-dip Layered Rock Slope[J]. Chin. J. Rock Mech. Eng. 31, 2214-2221. doi:10.3969/j.issn.1000-6915.2012.11.009

Zhang, H. N., Chen, C. X., Zheng, Y., Zhou, Y. C., and Deng, Y. Y. (2018). Analytical Study on Block-Flexure Toppling Failure of Rock Slopes Subjected to Seismic Loads[J]. China J. Highw. Transportation 31 (2), 75-85. doi:10.19721/ j.cnki.1001-7372.2018.02.008

Zhang, Z., Wang, T., Wu, S., and Tang, H. (2015). Rock Toppling Failure Mode Influenced by Local Response to Earthquakes. Bull. Eng. Geol. Environ. 75, 1361-1375. doi:10.1007/s10064-015-0806-x 
Zhao, J. J., Ju, N. P., Li, G., and Huang, R. Q. (2010). Failure Mechanism Analysis of Guantan Landslide Induced by Wenchuan Earthquake[J]. J. Geol. Hazards Environ. Preservation 21 (2), 92-96. doi:10.3969/j.issn.1006-4362.2010.02.021

Zheng, Y., Chen, C. X., Zhu, X. X., Ou, Z., Liu, X. M., and Liu, T. T. (2014). Analysis of Toppling Failure of Rock Slopes Subjected to Seismic Loads[J]. Rock Soil Mech. 35 (4), 1025-1032. doi:10.16285/j.rsm.2014.04.010

Zuo, B. C., Chen, C. X., Liu, X. W., and Shen, Q. (2005). Modeling experiment Study on Failure Mechanism of Counter-tilt Rock Slope[J]. Chin. J. Rock Mech. Eng. 24 (19), 3505-3511. doi:10.3321/j.issn:1000-6915.2005.19.017

Conflict of Interest: The authors declare that the research was conducted in the absence of any commercial or financial relationships that could be construed as a potential conflict of interest.
Publisher's Note: All claims expressed in this article are solely those of the authors and do not necessarily represent those of their affiliated organizations, or those of the publisher, the editors and the reviewers. Any product that may be evaluated in this article, or claim that may be made by its manufacturer, is not guaranteed or endorsed by the publisher.

Copyright $\odot 2022$ Zhang, Wu, Huang, Zheng and Miao. This is an open-access article distributed under the terms of the Creative Commons Attribution License (CC $B Y)$. The use, distribution or reproduction in other forums is permitted, provided the original author(s) and the copyright owner(s) are credited and that the original publication in this journal is cited, in accordance with accepted academic practice. No use, distribution or reproduction is permitted which does not comply with these terms. 